\title{
TEORIA COGNITIVA DA APRENDIZAGEM MULTIMÍDIA E JOGOS DIGITAIS
}

\section{COGNITIVE THEORY OF MULTIMEDIA LEARNING AND DIGITAL GAMES}

\author{
Ana Maria Ferreira Lemes Stafusa 1 \\ Mônica Romana de Oliveira Santos² \\ Valdinei Cezar Cardoso ${ }^{3}$
}

\begin{abstract}
Resumo
Este artigo possui abordagem exploratória de caráter qualitativo, cujo objetivo é analisar as características de jogos educativos digitais, a fim de verificarmos se possuem potencial para o ensino de matemática à luz da Teoria Cognitiva de Aprendizagem Multimídia. Buscamos responder ao seguinte questionamento: De que maneira a Teoria Cognitiva de Aprendizagem Multimídia pode contribuir para nortear os educadores na seleção de jogos educativos digitais para o ensino de matemática? O referencial teórico utilizado foi baseado nas publicações de Mayer. Analisamos três jogos: Jogos de Matemática, $1^{\text {a }}$ e $2^{\mathrm{a}}$ Séries: Jogos de Matemática para Crianças e Rei da Matemática. Concluímos que a Teoria Cognitiva da Aprendizagem Multimídia contribui na seleção de jogos educativos que tenham potencial para o ensino de matemática pois, foi possível identificar, por meio da análise realizada, os princípios para jogos desenvolvidos por Mayer que colaboram de forma positiva no processo de ensino-aprendizagem de matemática.
\end{abstract}

Palavras-chave: TCAM. Jogos Digitais. Ensino de Matemática.

\footnotetext{
${ }^{1}$ Mestranda do Programa de Pós-Graduação em Ensino na Educação Básica da Universidade Federal do Espírito Santo. E-mail: amflemes@gmail.com

${ }^{2}$ Mestranda do Programa de Pós-Graduação em Ensino na Educação Básica da Universidade Federal do Espírito Santo. E-mail: monicaromanasantos@gmail.com

${ }^{3}$ Doutor em Ensino de Ciências e Matemática pela Faculdade de Educação da Universidade Estadual de Campinas. Docente do Departamento de Matemática Aplicada do Centro Universitário Norte do Espírito Santo, da Universidade Federal do Espírito Santo. E-mail: v13dinei@ gmail.com
} 
Teoria cognitiva da aprendizagem multimídia e jogos digitais

\begin{abstract}
This article takes a qualitative exploratory approach with the objective of analyzing digital educational games features, with the purpose of verifying if they have potential for teaching math in the light of the Cognitive Theory of Multimedia Learning. We look to answer the following question: How can the Cognitive Theory of Multimedia Learning contribute to guide teachers in the selection of digital educational games for teaching math? We used Mayer's publications as a theoretical base. We analyzed three games, Jogos de Matemática (Math Games), $1^{\text {a }}$ e $2^{\text {a }}$ Séries: Jogos de Matemática para Crianças (1stand 2ndgrades: Math Games for Kids) and Rei da Matemática (Math's King). We concluded that the Cognitive Theory of Multimedia Learning contributes in selecting educational games which have potential for teaching math, because it was possible to identify through the analysis performed, the principles for games developed by Mayer that collaborate positively in the process of teaching-learning mathematics.
\end{abstract}

Keywords: CTML. Digital Games. Teaching Mathematics.

\title{
Introdução
}

O presente trabalho tem uma abordagem exploratória e de caráter qualitativo que parte da Teoria Cognitiva da Aprendizagem Multimídia (TCAM) desenvolvida por Richard E. Mayer, psicólogo e professor da Universidade da Califórnia, nos Estados Unidos. Consideramos que os princípios apontados por Mayer (2014) podem contribuir, significativamente, para o educador que deseja buscar uma melhor combinação de estímulos visuais e auditivos na seleção de jogos educativos digitais, tendo em vista a compreensão do conteúdo por parte dos estudantes.

No contexto de utilização de dispositivos digitais e da Internet, o qual vivenciamos atualmente, existem os jogos digitais que oferecem entretenimento por meio das redes sociais, aplicativos, programas de computador, sites ou console de jogos. Eles se tornam cada vez mais populares entre as pessoas, principalmente entre os jovens. Consideramos que as práticas de ensino devem estar alinhadas à realidade dos estudantes, acreditamos que o jogo digital pode ser um recurso promissor para o en- 
Teoria cognitiva da aprendizagem multimídia e jogos digitais

sino-aprendizagem da matemática. O sucesso dos jogos digitais está no encorajamento que estes podem proporcionar aos estudantes devido à "[...] combinação de motivação, engajamento, adaptabilidade, simulação, colaboração e coleção de dados" (GROS, 2015, p. 50, tradução nossa) ${ }^{4}$.

Dessa forma, surge a importância de discutir-se o papel desse recurso como instrumento de educação na sociedade, o que se justifica ao partir-se do princípio de que a tecnologia tem cada vez mais relevância na sociedade. Sendo assim, podemos apreciar a necessidade de desenvolver uma experiência de ensino integrada à nova realidade tecnológica. Justifica-se, então, o uso dos jogos educativos digitais na educação, tanto para promover a aprendizagem quanto para aquisição de competências necessárias à nova era digital.

A Base Nacional Comum Curricular (BNCC) indica o uso de tecnologias digitais como uma das competências gerais a ser obtida pelo estudante em seu percurso pela educação básica:

Compreender, utilizar e criar tecnologias digitais de informação e comunicação de forma crítica, significativa, reflexiva e ética nas diversas práticas sociais (incluindo as escolares) para se comunicar, acessar e disseminar informações, produzir conhecimentos, resolver problemas e exercer protagonismo e autoria na vida pessoal e coletiva. (BRASIL, 2017, p. 9)

A BNCC nos dá parâmetros para utilizarmos os jogos (digitais ou não) no ensino e buscarmos meios e metodologias para instigar o aluno. Moran (2013a, 2013b) defende que as tecnologias possibilitam meios favoráveis ao ensino, mas é necessário que sejam realizadas dinâmicas de formação docente sólidas, constantes e significativas para que sua utilização contemple todas as capacidades de instrução que esses recursos

\footnotetext{
$\overline{{ }^{4} \text { Citação Original: }}[\ldots]$ combination of motivation, engagement, adaptativity, simulation, collaboration and data collection.
} 
Teoria cognitiva da aprendizagem multimídia e jogos digitais

são capazes de possibilitar. Com isso, a TCAM busca nortear o trabalho docente na seleção ou elaboração de atividades didáticas, instruindo-o na busca pela melhor sintonia entre os estimulos visuais e auditivos presentes em animações, jogos digitais, vídeos, slides, livros, narração em computador, etc., que serão mais apropriados para serem utilizados com objeto de ensino. Mayer (2014) interessa-se também em determinar a eficácia dos jogos de computador sob os aspectos da aprendizagem multimídia.

Dessa forma, este artigo busca contribuições que possam orientar o trabalho docente no uso de jogos educativos, auxiliando aos que pretendem utilizar jogos digitais em suas práticas escolares. A questão que norteia este trabalho é: de que maneira a TCAM pode contribuir para nortear os educadores na seleção de jogos educativos digitais para o ensino de matemática? O objetivo deste artigo é analisar as caracteristicas de jogos educativos digitais, a fim de verificarmos se possuem potencial para o ensino de matemática à luz da Teoria Cognitiva de Aprendizagem Multimídia (TCAM), tendo como referencial teórico as publicações de Mayer (2001, 2014).

No conteúdo deste artigo, primeiramente, é realizado um levantamento de trabalhos anteriores relacionados ao tema de investigação. Depois, é apresentado o referencial teórico que será a TCAM. Em seguida, é feita uma análise dos jogos à luz dos princípios da aprendizagem multimídia. Por fim, são apresentadas as considerações finais.

\section{Contribuições de pesquisas similares}

Buscando por trabalhos que tenham pontos em comum com o que pretende-se desenvolver no presente trabalho, foi consultada a plataforma Google Acadêmico sendo nela utilizadas as palavras-chaves: "jogos digitais"; "TCAM"; "Mayer"; e especificando o período de 2017 até 2020, sendo então encontrados 44 artigos. Por meio da análise dos títulos, re- 
Teoria cognitiva da aprendizagem multimídia e jogos digitais

sumos e conclusões, os autores verificaram que apenas dois artigos estão alinhados com o que tema de investigação. Sendo assim, serão detalhadas as contribuições dos trabalhos abaixo elencados.

Os autores Cezarotto e Battaiola (2017) desenvolveram uma pesquisa qualitativa com abordagem exploratória com o título "Contribuições do aprendizado multimídia para jogos com foco nas dificuldades da matemática" tendo como questão norteadora "como os conceitos da TCAM podem contribuir para promover a eficácia em jogos eletrônicos utilizados na reabilitação neuropsicológica de crianças com Discalculia do Desenvolvimento?”. O artigo teve como objetivo apresentar os dados mapeados pelos autores que possam orientar os desenvolvedores no momento da configuração das informações e elementos de jogo, a fim de contribuir para a produção de recursos que atendam mais necessidades cognitivas e motivacionais de estudantes com discalculia do desenvolvimento. Os jogos digitais foram analisados à luz da TCAM, sendo eles: Jogo do Jacaré, Meister Cody e Number Catcher. Os autores observaram os princípios da modalidade, personalização, pré-treinamento e redundância.

A exploração dos jogos resultou no mapeamento de um conjunto de características e apontamentos que, de acordo com Cezarotto e Battaiola (2017), podem auxiliar os desenvolvedores na construção de jogos educacionais. Constataram também que os principios instrucionais propostos por Mayer (2014) discutidos no artigo podem contribuir para a criação de jogos mais próximos das necessidades cognitivas e motivacionais dos $\mathrm{u}-$ suários.

O segundo trabalho foi desenvolvido pelos pesquisadores Almeida Junior e Cardoso (2017) com o título "O Estado da Arte do Uso de Jogos Digitais para o Ensino de Física". Nele, os autores buscaram trabalhos sobre o ensino de física mediado por jogos digitais publicados no período de 2010 até 2015. Fizeram uma análise textual discursiva com o objetivo 
de ampliar a compreensão sobre trabalhos que tratam do uso de jogos digitais na disciplina de física no Ensino Médio e as ações do professor que podem favorecer o aprendizado conceitual neste campo do conhecimento, considerando também que o uso desses recursos durante tarefas de aprendizagem proporciona aos alunos, um processo cognitivo mais profundo em comparação com os métodos tradicionais de ensino. Eles também constataram que há poucos estudos experimentais na área de aprendizagem de física por meio de jogos digitais e indicaram que apenas um dos trabalhos referenciados por eles apoiou-se nos princípios da TCAM para fundamentar as características que potencializam os jogos digitais para o ensino de física. Concluíram, diante dos achados da investigação, que os jogos digitais podem auxiliar no processo de aprendizagem de fenômenos físicos de difícil visualização, e que o professor deve agir como mediador entre o objeto de aprendizagem (jogo digital) e o objetivo instrucional para a construção da aprendizagem.

\section{Metodologia da pesquisa}

A fim de obter os resultados e respostas relativas à problematização apresentada neste trabalho, os autores analisaram três jogos digitais educativos fundamentados na TCAM de Mayer (2001, 2014). Bogdan e Biklen (1994, p.16) ressaltam que a pesquisa qualitativa mostra-se adequada quando se trata de questões "formuladas com o objetivo de investigar fenômenos em toda a sua complexidade e em contexto natural". Assim, este estudo caracteriza-se como natureza qualitativa. Sendo também caracterizado como documental e bibliográfico, pois, "sempre que uma pesquisa se utiliza apenas de fontes documentais (livros, revistas, documentos legais, arquivos em mídia eletrônica), diz-se que a pesquisa possui estratégia documental” (APPOLINÁRIO, 2009, p. 85). Também, Sá-Silva, A1meida e Guindani $(2009$, p.5) afirmam que "tanto a pesquisa documental como a pesquisa bibliográfica têm o documento como objeto de investigação". 
Teoria cognitiva da aprendizagem multimídia e jogos digitais

A metodologia também tem objetivo exploratório, pois visa "proporcionar maior familiaridade com o problema, com vistas a torná-lo mais explícito ou a constituir hipótese. Pode-se dizer que estas pesquisas têm como objetivo principal o aprimoramento de idéias ou a descoberta de intuições" (GIL, 2002, p. 41).

A pesquisa encontra-se idealizada de acordo com as etapas a seguir:

$1^{\text {a }}$ Etapa: Pesquisa documental e bibliográfica realizada em meios físicos e digitais referentes à TCAM, jogos digitais e tecnologias na educação.

$2^{a}$ Etapa: Busca por jogos digitais educativos, disponiveis gratuitamente nas lojas virtuais de aplicativos para smartphones, tablets e computadores. Nesta busca utilizamos as palavras-chaves: "Jogos"; "matemática"; "educativos". Considerando os objetivos de ensino propostos na BNCC para aprendizagem de matemática, foram escolhidos três jogos: "Jogos de Matemática"; " $1^{\mathrm{a}}$ e $2^{\mathrm{a}}$ Série: Jogos de Matemática para Crianças" e "Rei da Matemática".

$3^{a}$ Etapa: Análise dos jogos, considerando a praticidade da sua interface; verificação se os jogos satisfazem os princípios multimídia para jogos, de Mayer (2014), a fim de perceber a potencialidade de ensino dos mesmos.

$4^{\text {a }}$ Etapa: Apresentação e discussão dos resultados.

\section{A Teoria Cognitiva da Aprendizagem Multimidia}

Buscou-se fundamentar esta pesquisa à luz de Mayer (2001), que se refere à instrução multimídia como a apresentação do material instrucional utilizando palavras e imagens com o intuito de promover a aprendizagem. De acordo com o autor, os estudantes podem entender melhor uma explicação quando são utilizadas palavras (narrações) e imagens do que 
quando são utilizadas apenas palavras escritas. Afirma ainda que as palavras podem ser impressas ou narradas; as imagens podem ser estáticas, como ilustrações ou fotografias, ou dinâmicas, como vídeos, animações e jogos. No entanto, o autor alerta que associar imagens a palavras descuidadas não garante que a aprendizagem ocorra e que o excesso de palavras, sons ou imagens pode fazer com que a mensagem principal não seja compreendida, pois a sobrecarga de informações divide a atenção dos estudantes. Assim, a TCAM auxilia no planejamento ou escolha de materiais instrucionais que sejam mais adequados, direcionados e capazes de proporcionar aprendizagem.

A TCAM admite que o sistema de processamento de informação humano baseia-se em três principios básicos:

(1) principio de dois canais - o processamento de informações ocorre em dois canais separados, sendo eles o visual/pictórico e o auditivo/verbal;

(2) princípio da capacidade limitada - cada um desses canais possui capacidade limitada de processamento de informações, ou seja, as pessoas podem processar apenas alguns elementos em cada canal na memória de trabalho;

(3) principio do processamento ativo - uma aprendizagem ativa implica no envolvimento apropriado das pessoas durante o processamento das informações (MAYER, 2014). 
Teoria cognitiva da aprendizagem multimídia e jogos digitais

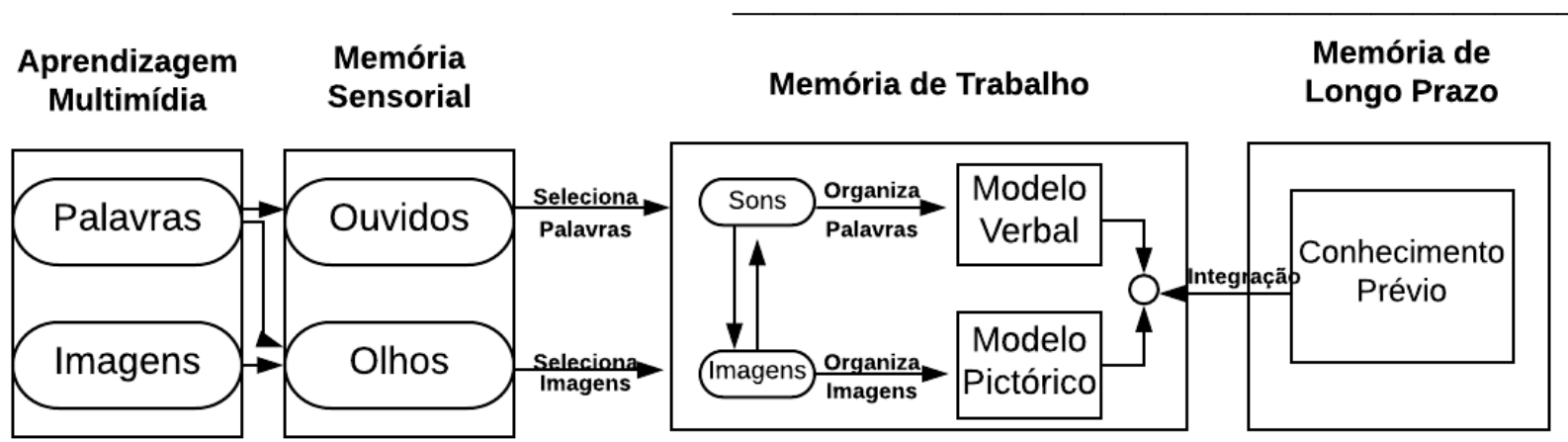

Figura 1: Teoria Cognitiva da Aprendizagem Multimídia.

Fonte: Adaptado de Mayer (2014, p. 78, tradução dos autores)

De acordo com Mayer (2001), a instrução multimídia entra no sistema de processamento de informação do indivíduo através dos ouvidos (narrações, sons) e dos olhos (palavras e imagens) levando à memória sensorial onde são mantidos por um breve período. Em seguida, ocorre a seleção de palavras e imagens relevantes e a transferência para a memória de trabalho, onde o indivíduo organiza mentalmente as informações verbais recebidas em uma representação verbal coerente (ou modelo verbal) e organiza as informações visuais recebidas em uma representação pictórica coerente (ou modelo pictórico).

Finalmente, o indivíduo ativa a memória de longo prazo na busca de conhecimentos prévios relevantes, trazendo-os à memória de trabalho, para serem integrados aos modelos verbais e pictóricos. O aprendizado construído na memória de trabalho será armazenado na memória de longo prazo (MAYER, 2001). Sendo assim, uma aprendizagem ativa ocorre quando o indivíduo se envolve em processos cognitivos apropriados, incluindo a seleção de informações relevantes, organizando-as mentalmente em uma representação verbal e pictórica coerente e integrando-as mentalmente a conhecimentos anteriores (MAYER, 2014).

No contexto dos jogos eletrônicos, a TCAM busca determinar como as pessoas podem aprender conteúdos escolares por meio deste recurso. De acordo com Mayer, "se desejamos criar ou selecionar jogos eficazes 
Teoria cognitiva da aprendizagem multimídia e jogos digitais

para a aprendizagem, é apropriado entender como funciona o aprendizado, como funciona a avaliação e como funciona a instrução" (MAYER, 2014 , p. 77 , tradução dos autores) ${ }^{5}$. O autor argumenta também que, para compreendermos a eficácia dos jogos eletrônicos na instrução, temos que considerar que, para aprender, os estudantes precisam se envolver em processos cognitivos adequados (processamento ativo), incluindo palavras e imagens enquanto jogam (canal duplo), levando em conta também, que o indivíduo apresenta capacidade limitada no processamento das informações.

Mayer (2014) considera como jogos eletrônicos para aprendizagem, os videogames, jogos digitais, jogos de computadores e jogos de simulações que tenham como objetivo promover mudanças perceptiveis no desenvolvimento escolar ou nas habilidades cognitivas dos estudantes e não apenas oferecer entretenimento. Estes jogos são interativos e baseiam-se em regras, oferecem uma resposta rápida e adequada ao jogador, são desafiadores, motivadores e bastante atrativos aos usuários. No entanto, o excesso de imagens, sons e movimento, que também são características dos jogos eletrônicos, pode sobrecarregar o processamento cognitivo do indivíduo diminuindo a oportunidade de aprendizagem. De acordo com Mayer (2014), os elementos dos jogos podem afetar os três tipos de processamento cognitivo do indivíduo:

[...] processamento estranho é causado por distração proporcionada pelos elementos presentes no design do jogo; processamento essencial é causado pela complexidade do conteúdo a ser aprendido; e processamento generativo é causado pela motivação do jogador para aprender, que pode ser estimulada pelo design emocionante do jogo. O desafio para projetar jogos eficazes é reduzir recursos de distração (diminuir o processamento estranho), aprimorar recursos motivadores (promover processamento generativo) e apresentar o conteúdo acadêmico de maneira que gerem o pro-

${ }^{5}$ Citação Original: If we want to create or select effective games for learning, it is useful to understand how learning works, how assessment works, and how instruction works. 
Teoria cognitiva da aprendizagem multimídia e jogos digitais

cessamento essencial (MAYER, 2014, p. 90, tradução dos autores) $^{6}$.

Sendo assim, um modelo eficaz de jogo eletrônico é aquele que estimula a motivação para aprender, mas não interfere no desempenho cognitivo durante a aprendizagem. Em sua pesquisa, Mayer (2014) descreve os princípios que visam reduzir o processamento estranho, gerenciar o processamento essencial e estimular o processamento generativo, a fim de promover o equilíbrio nas características de entretenimento e de instrução dos jogos de computador para que os objetivos de aprendizagem sejam alcançados. Estes princípios podem orientar tanto os desenvolvedores que pretendem criar jogos educativos digitais eficazes, quanto os educadores que pretendem ensinar por meio deste recurso. A seguir, descreveremos os princípios instrucionais para jogos educativos de computador, estruturados por Mayer (2014).

\subsection{Principios para reduzir o processamento estranho para jogos}

Princípio da redundância: Pessoas não aprendem melhor quando um jogo inclui palavras na tela junto com a narração, em vez de narrações apenas. Para Mayer (2014) apresentar textos impressos na tela e narração juntos, pode gerar uma sobrecarga no processamento cognitivo, pois, o estudante irá gastar sua capacidade limitada de processamento tentando conciliar as duas formas verbais no canal de entrada, além de ter sua atenção no canal visual dividida, ou seja, pode perder parte da animação enquanto ler a legenda, ou perder parte da legenda enquanto

\footnotetext{
$\overline{{ }^{6} \text { Citação Original: }}$ [...] extraneous processing is caused by distracting game design; essential processing is caused by the complexity of the to-be-learned material; and generative processing is caused by the game player's motivation to learn as stimulated by exciting game design. Overall, the challenge of designing games for learning is to reduce distracting features (and thereby reduce extraneous processing), hone motivating features (and thereby foster generative processing), and present academic content in ways that manage essential processing.
} 
Teoria cognitiva da aprendizagem multimídia e jogos digitais

visualiza a animação. A solução é que as palavras sejam apresentadas apenas na forma de narração (MAYER, 2014).

Princípio de coaching: Pessoas aprendem melhor com um jogo quando recebem avisos ou explicações ao longo do jogo. De acordo com Mayer (2014), estudantes podem ficar sobrecarregados com as características perceptivas do jogo e com os movimentos motores que devem executar enquanto jogam, perdendo a concentração, distraindo-se da mensagem instrucional. Ao receber avisos ou explicações (por exemplo, receber uma explicação na tela após cada decisão importante no jogo; ou um aviso de que pode estar escolhendo o caminho errado), são estimulados a prestarem atenção nas informações essenciais quando jogam, reduzindo o processamento estranho e resultando em aprendizagem (MAYER, 2014).

Princípio da imersão: Pessoas não aprendem melhor quando um jogo é renderizado em realidade virtual 3D ao invés de 2D. De acordo com Mayer (2014), aumentar o realismo do jogo pode acrescentar detalhes estranhos à percepção do estudante concorrendo com a capacidade limitada de processamento do estudante. Mudar a renderização de jogos 2D para renderização $3 \mathrm{D}$, pode diminuir o aprendizado, distraindo o estudante de se envolver em processamento cognitivo adequado. Quando o sistema cognitivo do individuo se concentra no processamento dos detalhes proporcionado pela realidade virtual, torna-se indisponivel para incorporar-se no processamento essencial e no processamento generativo (MAYER, 2014).

Destacamos que os princípios de imersão e redundância são exemplos de características do jogo que mostram não melhorar o aprendizado e que devem ser evitados a fim de diminuir o processamento de informações irrelevantes (MAYER, 2014). 
Teoria cognitiva da aprendizagem multimídia e jogos digitais

\subsection{Princípios para gerenciar o processamento essencial para jogos}

Princípio da modalidade: Pessoas aprendem melhor com um jogo quando as palavras são narradas em vez de impressas na tela. De acordo com Mayer (2014), o canal visual do estudante pode ficar sobrecarregado quando o jogo inclui texto impresso na tela. Os aprendizes dividem sua atenção entre ler as palavras ou visualizar a imagem do jogo sobrecarregando o canal visual. Essa situação pode ser reduzida na medida em que as imagens são captadas pelo sistema cognitivo por meio dos olhos enquanto as narrações são captadas pelos ouvidos (MAYER, 2014).

Princípio do pré-treinamento: De acordo com esse princípio, os jogadores aprendem melhor quando recebem pré-treinamento nos nomes e características dos principais conceitos do jogo. Nesse princípio, Mayer (2014) afirma que obter experiências pré-jogo permite aos jogadores utilizarem seus recursos cognitivos para construir conexões entre os conceitos-chave e conceitos essenciais para a resolução do problema, ao invés de ter que aprender nomes e características do jogo.

\subsection{Principios para estimular o processamento generativo para jogos}

Princípio da personalização: Pessoas aprendem melhor em um jogo quando as palavras são apresentadas num estilo informal (conversação) ao invés de utilizar linguagem formal. Para Mayer (2014), quando o estudante percebe o computador como um parceiro social ao invés de percebê-lo como uma máquina, ele se sente mais motivado. O estilo de conversação informal encoraja o estudante a usar sua capacidade de processamento cognitivo disponivel para compreender mais profundamente os conceitos propostos no jogo, o que resulta em melhores resultados de aprendizado (MAYER, 2014). 
Teoria cognitiva da aprendizagem multimídia e jogos digitais

Princípio autoexplicativo: Pessoas aprendem melhor em um jogo quando são solicitadas a dar explicações durante o jogo. De acordo com Mayer (2014), quando os estudantes são incentivados a explicar o conteúdo do jogo (por exemplo, escolhendo uma explicação compativel com sua estratégia de jogo a partir de uma lista disponivel na interface), podese favorecer um processamento cognitivo generativo mais profundo e um melhor aprendizado.

\section{Apresentação e análise dos jogos digitais de acordo com os principios instrucionais}

Dispositivo digital, conforme Mayer (2017), é qualquer meio eletrônico controlado por um chip de computador, dentre os quais, o próprio computador, tablet, smartphones, dentre outros. Também se pode afirmar que "a Internet, as redes, o celular, a multimídia estão revolucionando nossa vida no cotidiano" (MORAN, 2013a, p. 1) e que as "estatísticas mostram que as pessoas estão vivendo cada vez mais, trabalhando cada vez menos e utilizando inúmeros suportes tecnológicos para facilitar a vida cotidiana" (PAIS, 2005, p. 130).

No momento da escolha, conforme descrição apontada na $2^{\mathrm{a}}$ Etapa dessa pesquisa, nos deparamos com um grande número de jogos, a maioria deles indicados para estudantes da Educação Infantil ou anos iniciais do Ensino Fundamental. Para fazer nossa seleção dentre tantas possibilidades, buscamos por aqueles que se mostraram capazes de "fomentar a aprendizagem relacionada aos objetivos escolares" (MAYER, 2014, p. 25, tradução nossa) 7 . Para isso, foram considerados se os conceitos matemáticos trabalhados atendem aos objetivos de aprendizagem e desenvolvimento propostos na BNCC: "desenvolver o pensamento numérico, que

$\overline{{ }^{7} \text { Citação original: }[\ldots]}$ the main goal of games for learning is to foster learning related to academic learning objectives. 
implica o conhecimento de maneiras de quantificar atributos de objetos e de julgar e interpretar argumentos baseados em quantidades"; considerando a unidade temática "Números" na qual o documento ressalta que "no estudo desses campos numéricos, devem ser enfatizados registros, usos, significados e operações” (BRASIL, 2017, p. 268).

\subsection{Análise do jogo "Jogos de Matemática"}

Começamos por apresentar o "Jogos de Matemática" (Figura2), que foi desenvolvido pela empresa Standy Software.

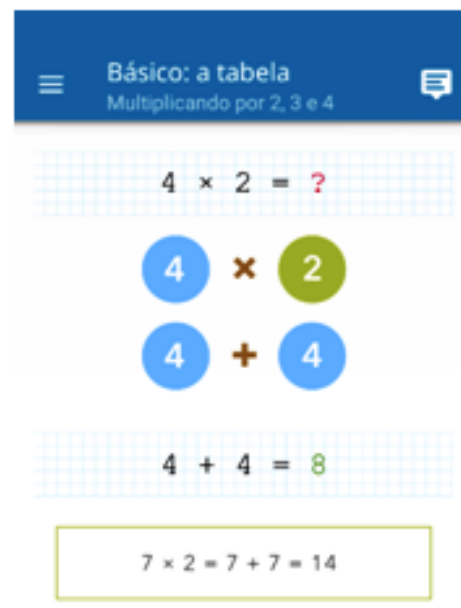

Figura 2: Jogos de Matemática: "Aprendendo"

Fonte: Interface de "Jogos de Matemática"

A proposta dos desenvolvedores é que o jogo proporciona treinamento para desenvolver habilidades matemáticas e aprender aritmética mental. Permite comparar pontuações com outros jogadores quando se utiliza o login de usuário da plataforma Google Play Games, o que o torna 
Teoria cognitiva da aprendizagem multimídia e jogos digitais

desafiador e emocionante para o jogador. Os conteúdos matemáticos trabalhados são adição, subtração, multiplicação, divisão, números quadrados e raiz quadrada. O jogo é indicado para estudantes do Ensino Fundamental ou pessoas que desejam treinar suas habilidades em cálculos matemáticos.

Percebemos o princípio do pré-treinamento na seção "Aprendendo" na qual o jogador pode optar por receber instruções básicas sobre a operação na qual deseja treinar suas habilidades para o cálculo mental. Tomamos, como exemplo, a operação de multiplicação (Figura 2), na qual o produto $4 \times 2$ é apresentado como uma adição de duas parcelas na forma das equações $4+4=8$ e $7 \times 2=7+7=14$.

A seção "Aprendendo" apresenta conceitos básicos sobre as operações cujas habilidades de cálculo mental serão treinadas no jogo. Isso permite que o jogador compreenda conceitos próprios da operação que irá escolher, antes de jogar. Esta ação atua no gerenciamento do processamento essencial, pois, o conhecimento adquirido poderá ser utilizado para resolver novos problemas, não sobrecarregando o processamento cognitivo. Dessa forma, caracteriza o princípio do pré-treinamento: Os jogadores aprendem melhor quando recebem pré-treinamento nos nomes e características dos principais conceitos do jogo (MAYER, 2014).

Continuemos utilizando como exemplo a operação de multiplicação. Dessa vez na seção de "Treinamento", a qual permite uma interação diversificada com o jogador. Para apresentar esta funcionalidade, apresentamos os itens da tela do jogo como F1 a F8 (Figuras 3 e 4) a fim de obtermos um melhor detalhamento de suas funções. 


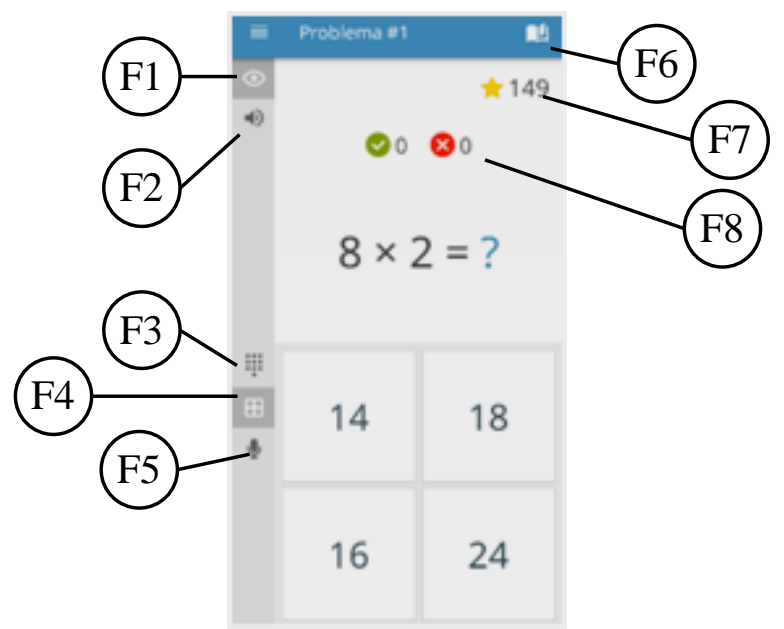

Figura 3 - Jogos de Matemática: "Treinamento" Fonte: Interface de "Jogos de Matemática".

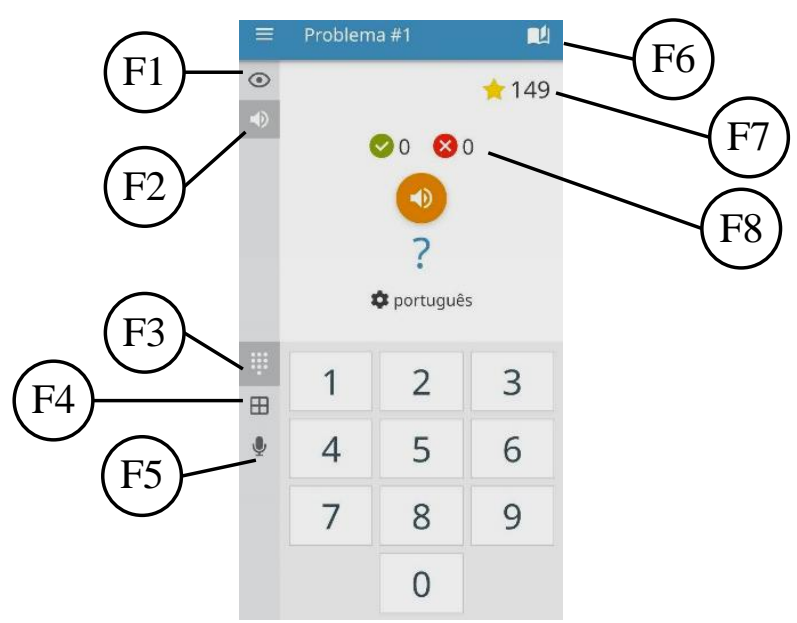

Figura 4 - Jogos de Matemática: "Treinamento"

Fonte: Interface de "Jogos de Matemática". 
Os ícones F1 e F2 servem para selecionar-se o modo de visualização do problema dado, sendo que o F1 apresenta o problema escrito na tela utilizando os algarismos indo-arábicos e o F2 como narração sonora por meio do alto-falante. Os ícones F3, F4 e F5 referem-se à forma como o jogador pode entrar com sua resposta: digitando-a no teclado numérico (F3); escolhendo-a na caixa de seleção (F4) ou falando pelo microfone do aparelho que está sendo utilizando (F5). O ícone F6 serve para voltar para o modo "Aprendendo". O ícone F7 mostra o número de pontos acumulados e o ícone F8 a quantidade de acertos e erros.

Percebemos que a opção por visualizar o problema ou ouvir o problema não irá sobrecarregar os canais auditivo e visual do jogador, reduzindo o processamento estranho. Além disso, o jogo não apresenta imagens ou palavras impressas na tela junto com a narração. Assim, não há redundância na apresentação dos problemas, diminuindo a possibilidade de processamento cognitivo ocasionado por informações desnecessárias. Notamos ainda, que ao optar pela apresentação do problema na forma de narração (Figura 4), evidencia-se o princípio da modalidade no qual Mayer (2014) considera que pessoas aprendem melhor com um jogo quando as palavras são narradas em vez de impressas na tela, ajudando a utilizar cada canal de processamento individualmente, sem sobrecarga de informação e promovendo o processamento cognitivo de informações essenciais ao aprendizado.

Quando o jogador opta por ouvir os problemas, ao invés de vê-los na tela, podemos observar o princípio da personalização. Quando o problema é narrado, o jogador pode perceber o aparelho como um parceiro social, motivando-o a dar sequência ao jogo, contribuindo assim para estimular o processamento generativo e dando sentido ao conteúdo abordado (MAYER, 2014). Observamos também, que o jogo é apresentado no formato 2D contribuindo para diminuir o processamento estranho. Sendo 
Teoria cognitiva da aprendizagem multimídia e jogos digitais

assim, caracteriza-se a ausência do princípio da imersão, que é um exemplo de característica de jogo que não melhora o desempenho.

Percebemos que, nesse jogo, são utilizadas poucas imagens ilustrativas, o que pode diminuir o processamento estranho e contribuir para estimular o processamento do conteúdo essencial. Por outro lado, a ausência de imagens, que são elementos de entretenimento, pode desmotivar o jogador mais facilmente, diminuindo a disposição para engajar-se no processamento generativo. Porém, o equilíbrio pode ser restaurado levando em consideração o modo desafiador do jogo que permite a competição com outros jogadores da plataforma Google Play Games, além de poder progredir no seu nível de conhecimento na medida em que treina e sua pontuação aumenta. Os efeitos motivadores das características do jogo incluem encorajar o jogador a iniciar, manter e envolver-se intensamente no jogo (MAYER, 2014).

\subsection{Análise do jogo " $1^{a}$ e $2^{a}$ Séries: Jogos de Matemática para Crianças"}

O jogo " $1^{a}$ e $2^{a}$ Séries: Jogos de Matemática para Crianças", como o nome já sugere, é indicado para estudantes do primeiro e segundo anos do Ensino Fundamental, ou seja, adequado para crianças de 6 a 8 anos. Foi desenvolvido pela empresa Edugames. A proposta dos desenvolvedores é desenvolver habilidades de matemática mental e resolver problemas de adição, subtração, multiplicação, divisão, frações, contagem, comparação e reconhecimento de formas geométricas.

A Figura 5 mostra a interface do jogo, que é colorida, com personagens atrativos para crianças e apresenta os problemas na forma de narração. Ao finalizar um grupo de problemas, o jogador ganha uma estrela. Pode optar também por um jogo da memória correspondente ao tema escolhido. Foi escolhido o tema "Multiplicação" para exemplificar. 


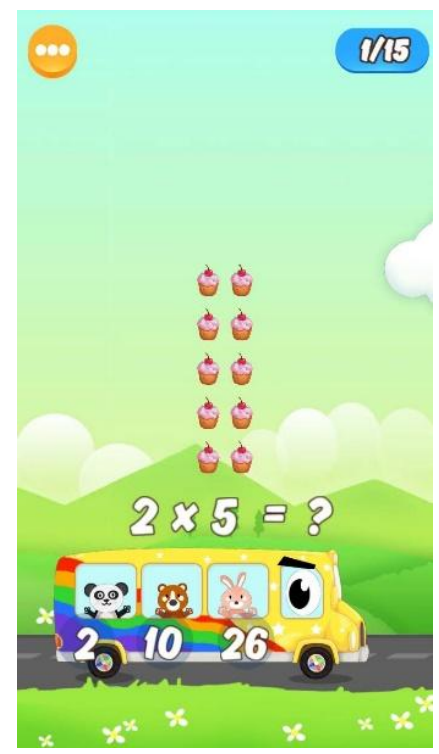

Figura 5: $1^{\mathrm{a}}$ e $2^{\mathrm{a}}$ Séries: Jogos de Matemática para Crianças: "Multiplicação". Fonte: Interface do Jogo $1^{\mathrm{a}}$ e $2^{\mathrm{a}}$ Séries: Jogos de Matemática para Crianças.

Na Figura 5, percebemos que o jogo apresenta a operação escrita na tela utilizando os algarismos indo-arábicos $(2 \times 5=?$; canal visual); representação por meio de dois grupos com imagens de cinco tortas de morango em cada um (pictórica - canal visual). A operação é apresentada, também, na forma de narração (canal auditivo). Além disso, existem outros elementos na interface que disputam a capacidade limitada de processamento no canal visual do jogador. Constatamos o princípio da redundância, em que a utilização repetitiva de conceitos acarreta em sobrecarga de informações, resultando num processamento cognitivo inadequado. Neste caso, os elementos concorrem no canal visual gerando um processamento estranho. Conforme já citado anteriormente, este princípio aponta elementos do jogo que não melhoram a aprendizagem.

No entanto, como se trata de um jogo voltado para crianças na faixa etária de 6 a 8 anos, a redundância na apresentação do problema pode 
ajudar a compreensão dos conceitos por parte dos estudantes. Nesta fase, as crianças ainda não são totalmente familiarizadas com os símbolos matemáticos. Isso pode deixar a mensagem complicada para elas. É necessário também, nesta faixa etária, que ocorra a associação entre essas três formas de representação para que se solidifique o entendimento sobre os conceitos da operação explorada no jogo. Mayer afirma que "[...] podem ser que os textos na tela sejam úteis quando o material é técnico, quando a mensagem é complicada ou quando o jogo não está na língua nativa do jogador" (MAYER, 2014, p. 132) ${ }^{8}$. Cezarotto e Battaiola (2017) também consideraram a redundância como um fator positivo quando é direcionada à crianças com limitações cognitivas, como por exemplo, as ocasionadas pelo Distúrbio de Discalculia.

A apresentação do problema na forma de narração, conforme citado anteriormente, é uma evidência do Princípio da Modalidade que, de acordo com Mayer (2014), é a maneira mais eficiente de apresentar as informações instrucionais, pois as imagens entram no sistema cognitivo através dos olhos enquanto as palavras entram nos ouvidos, equilibrando a capacidade de processamento disponível nesses dois canais, processando o que é essencial contribuindo para que ocorra aprendizagem.

Percebemos, ainda, o princípio da personalização. Além dos problemas serem propostos na forma narrada, o jogo transmite mensagens de encorajamento. Após cada acerto, o jogador ouve o narrador em voz informal dizer "Muito bem", "Fantástico", "Excelente", "Bom trabalho", "Impressionante", etc. Quando erra, o jogador ouve "Não, Não, Não" em voz infantilizada. Como já comentamos anteriormente, este estilo de conversação motiva o jogador, pois o ajuda a ver o aparelho como um parceiro social, ajudando-o a focar no conteúdo essencial e usar a sua capaci-

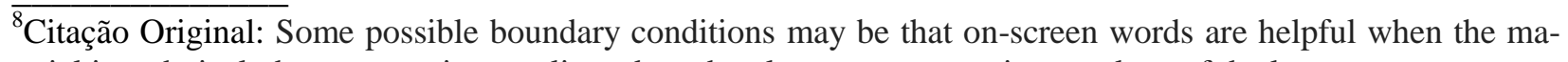
terial is technical, the message is complicated, or the players are not native speakers of the language. 
Teoria cognitiva da aprendizagem multimídia e jogos digitais

dade cognitiva para compreender os conceitos, ativando o processamento generativo.

Percebemos, também, o princípio do pré-treinamento quando o tema escolhido é geometria, conforme nos mostram as Figuras 6, 7, 8 e 9.

Figura 6

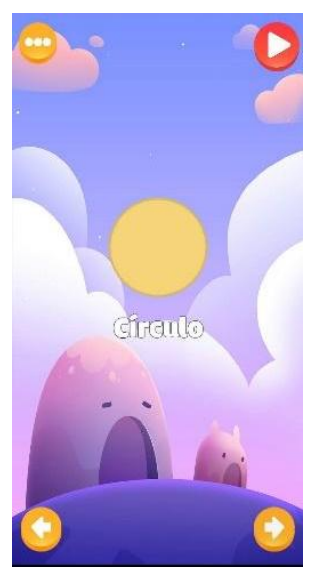

Figura 7

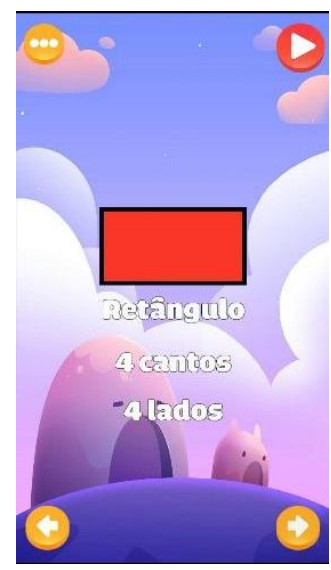

Figura 8

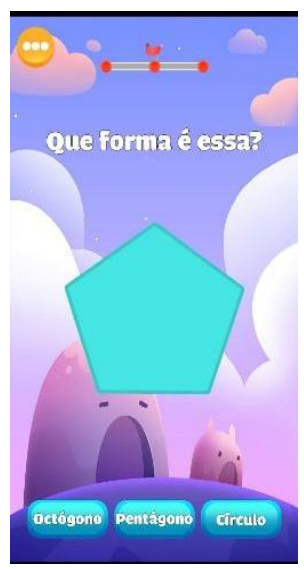

Figura 9

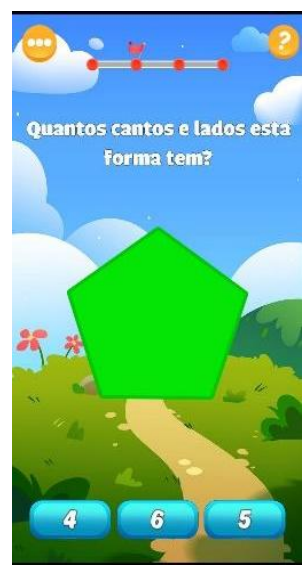

$1^{a}$ e $2^{a}$ Séries: Jogos de Matemática para Crianças: "Geometria".

Fonte: Interface do Jogo $1^{\mathrm{a}}$ e $2^{\mathrm{a}}$ Séries: Jogos de Matemática para Crianças.

A primeira opção de interação no tema "Geometria" permite conhecer as principais formas geométricas planas. Nesta seção, as formas geométricas são apresentadas, uma a uma, por meio de narração e texto escrito na tela (onde, mais uma vez, percebemos o princípio da redundância) conforme a Figura 6.

A Figura 7 mostra a interface quando é apresentado o nome da forma geométrica, o número de cantos (vértices) e o número de lados por meio de narração e texto em tela. As Figuras 6 e 7 são exemplos de onde constatamos o princípio do pré-treinamento, pois, permite que o jogador 
Teoria cognitiva da aprendizagem multimídia e jogos digitais

receba instruções sobre os nomes e características das formas geométricas, antes de resolver os problemas.

Na Figura 8, a interface mostra que, nesta fase, o jogador irá resolver problemas sobre os nomes das formas, conforme treinamento recebido na fase anterior; ou resolver problemas relacionados ao número de vértices e de lados da figura, conforme Figura 9. Há outras possibilidades de atividades, como por exemplo, identificar o "círculo" entre diversas formas geométricas. O jogo possibilita, também, que o nome da forma geométrica seja narrado quando o jogador toca sobre a imagem na tela. Esses recursos de interatividade são motivadores e possibilitam que o estudante se concentre nos conteúdos escolares, ocasionando o gerenciamento do processamento cognitivo essencial e o estímulo ao processamento generativo (MAYER, 2014).

Observamos, ainda, que o jogo está em formato 2D, contribuindo para reduzir a possibilidade de distração com elementos proporcionados pela realidade virtual (processamento estranho), o que poderia ocorrer caso fosse renderizado em $3 \mathrm{D}$, justificando a ausência do princípio da imersão. Sendo assim, o estudante envolve-se num processamento cognitivo com a redução das distrações e incorpora-se no processamento essencial e generativo, melhorando a aprendizagem (MAYER, 2014).

\subsection{Análise do jogo "Rei da Matemática"}

Analisamos, ainda, o jogo "Rei da Matemática", indicado para estudantes na faixa etária de 5 a 8 anos, desenvolvido pela empresa Oddrobo Software $A B$. A versão gratuita contempla problemas de matemática relacionados à contagem e operações básicas. O objetivo do jogo é treinar as operações matemáticas elementares e resolver os problemas dos grupos de contagem, adição e miscelânea, para conseguir o maior número de estrelas, ganhar medalhas de bronze, prata e ouro e mudar de nível. O jo- 
gador deve ler o problema e escolher sua resposta numa caixa de seleção. A interface do jogo (Figura 10) é atrativa para crianças e fácil de usar. Não existe redundância, pois não há repetição na forma de apresentação dos problemas, que são apresentados por meio de imagens e palavras na tela.

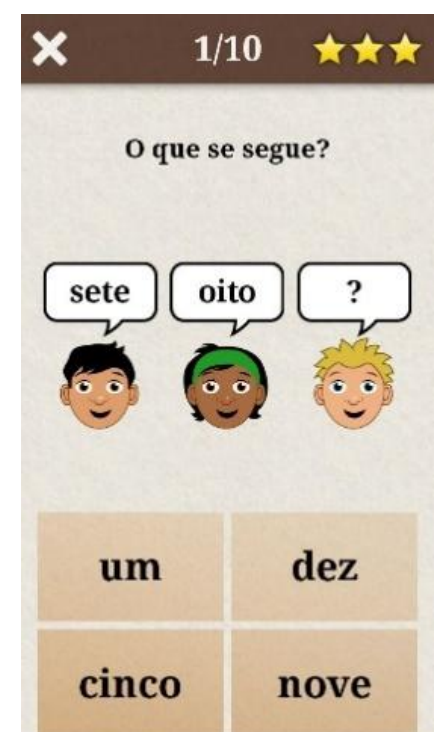

Figura 10 - Jogo Rei da Matemática: "Contagem"

Fonte: Interface do Jogo Rei da Matemática

Percebemos a ausência do princípio da modalidade, pois os problemas não são apresentados na forma de narração, mas sim, no formato de texto seguido de imagem, o que pode dividir a atenção no canal visual comprometendo a capacidade limitada de processamento. Destacamos, também, a ausência do princípio da imersão, pois, o jogo é renderizado em 2D - o que é positivo por não apresentar distrações que possam comprometer o aprendizado.

Apesar de ser atrativo e de simples interface, os baixos recursos de interatividade podem significar um baixo interesse do estudante em continuar o jogo. Para Mayer (2014), um jogo de computador eficiente deve 
Teoria cognitiva da aprendizagem multimídia e jogos digitais

motivar o estudante a continuar jogando a fim de terem os objetivos de aprendizagem alcançados.

\subsection{Comparativo dos jogos analisados}

A Tabela 1 resume o que encontramos na análise dos três jogos considerando os princípios instrucionais para jogos educativos de computador de Mayer (2014). Nela, os princípios da redundância e imersão (marcados com os asteriscos) são os que não contribuem para melhoria no aprendizado, pois, potencializam o processamento daquilo que não é essencial no jogo. Não ser redundante na apresentação da instrução e não ser renderizado em 3D são características que devem ser observadas quando pretende-se diminuir o processamento de informações alheias ao que se pretende ensinar por meio de um jogo digital. Percebemos que, apenas o jogo " $1^{\mathrm{a}}$ e $2^{\mathrm{a}}$ Séries - Jogos de Matemática para Crianças" possui redundância. No entanto, é possível que este princípio, conforme contemplado nos princípios propostos por Mayer (2014), não represente neste caso, um obstáculo para aprendizagem, por se tratar de um jogo voltado para crianças em fase de aprendizagem da escrita e de associação das operações matemáticas à símbolos e modelos pictóricos.

Tabela 1 - Princípios observados nos jogos analisados

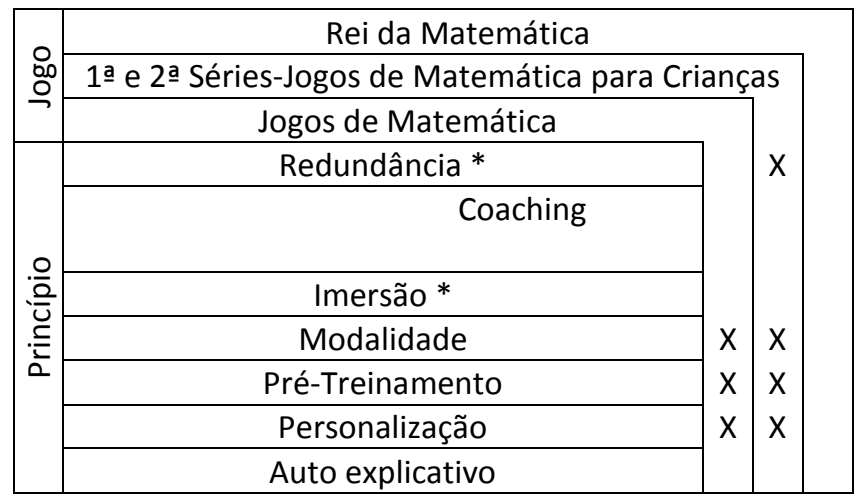

Fonte: Os autores 
Os princípios de imersão, modalidade e personalização são aqueles que possuem caracteristicas que provocam melhoria no aprendizado do jogador e que foram observados em "Jogos de Matemática" e " $1^{\mathrm{a}}$ e $2^{\mathrm{a}}$ Séries - Jogos de Matemática para Crianças”. Além de diminuir o processamento estranho, estes principios caracterizam-se também por gerenciar o processamento essencial, fazendo com que o estudante se concentre no que é relevante, ou seja, no conteúdo instrucional e o motive a incorporar-se no processamento generativo, resultando em uma aprendizagem mais efetiva. O jogo "Rei da Matemática" não contemplou nenhum desses princípios.

Os principios de coaching e autoexplicativo caracterizam-se também por provocar melhoria na aprendizagem. No entanto, não foram observados em nenhum dos três jogos. Acreditamos que estes princípios tornariam os jogos analisados mais adequados à aprendizagem.

Constatamos, então, diante da análise realizada, que "Jogos de Matemática” e " $1^{\mathrm{a}}$ e $2^{\mathrm{a}}$ Séries - Jogos de Matemática para Crianças" estão alinhados aos princípios instrucionais para jogos educativos de computador observados por Mayer (2014). De fato, foi possivel perceber, a partir da TCAM, que estes recursos podem proporcionar um ambiente de interação e motivação apropriado à aprendizagem dos estudantes.

\section{Considerações finais}

Richard Mayer, por meio da Teoria Cognitiva da Aprendizagem Multimídia, se propõe a investigar maneiras eficientes para a elaboração e seleção de recursos instrucionais capazes de promover uma aprendizagem mais efetiva a partir do balanceamento entre os estímulos auditivos

e visuais presentes no material de ensino. Assim, desenvolvemos esta pesquisa a fim de verificar de que maneira a TCAM pode contribuir para 
Teoria cognitiva da aprendizagem multimídia e jogos digitais

nortear os educadores na seleção de jogos educativos digitais para o ensino de matemática. Para alcançar nosso objetivo, selecionamos três jogos disponíveis para tablets e smartphones, os quais analisamos detalhadamente suas características à luz da Teoria Cognitiva de Aprendizagem Multimídia. Verificamos, em dois deles, os princípios de Pré-Treinamento, Modalidade e Personalização. Percebemos também a ausência dos princípios Coaching e Autoexplicativo. Então, notamos que a teoria de Mayer pode, de fato, nortear os educadores que pretendem utilizar jogos digitais como recurso didático em suas aulas, no sentido de fundamentar a busca por materiais instrucionais, sejam eles jogos, slides, vídeos, que tenham potencial de ensino.

Concordamos com Gros (2015) e acreditamos que os "jogos fornecem uma oportunidade para que estudantes se engajem completamente em aprender para obter sucesso" (GROS, 2015, p. 39, tradução nossa) ${ }^{9}$. Diante da pesquisa realizada, chegamos à conclusão que os jogos educativos estudados podem melhorar e estimular o aprendizado, ajudando o entendimento dos conteúdos matemáticos e que quando são desenvolvidos de acordo com os princípios da TCAM, a interação se torna agradável para os estudantes. Nesses tempos tecnologicamente globalizados, os jogos digitais proporcionam diversão e podem despertar o interesse do aluno e estimular o seu aprendizado.

\section{Referências}

ALMEIDA JUNIOR, Edson Ribeiro de Britto de; CARDOSO, Valdinei Cezar. O estado da arte do uso de jogos digitais para o ensino de Física. ENCONTRO INTERNACIONAL DE PRODUÇÃO CIENTÍFICA, 10., 2017, Maringá. Anais... Maringá: Unicesumar, 2017.

Disponivel em: http://rdu.unicesumar.edu.br/handle/123456789/1727. Acesso em: 18 ago. 2020.

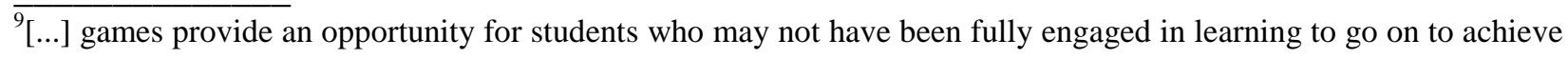
success. 
APPOLINÁRIO, Fábio. Dicionário de Metodologia Científica: um guia para produção do conhecimento científico. São Paulo: Atlas, 2009.

BRASIL. Base Nacional Comum Curricular. Educação é a Base. Brasília: MEC/CONSED/UNDIME, 2017.

Disponivel em: http://basenacionalcomum.mec.gov.br/abase. Acesso em: 17 ago. 2020.

BOGDAN, Robert C.; BIKLEN, Sari K. Investigação qualitativa em educação. Porto: Porto Editora, 1994.

CEZAROTTO, Matheus Araújo; BATTAIOLA, André Luiz: Contribuições do aprendizado multimidia para jogos com foco nas dificuldades da matemática. Porto: Edições Universidade Fernando Pessoa, 2017.

Disponivel em: https://bdigital.ufp.pt/handle/10284/6010. Acesso em: 22 jul. 2020.

GIL, Antônio Carlos. Como elaborar projetos de pesquisa. 4. ed. São Paulo: Atlas, 2002.

GROS, Begoña. Integration of digital games in learning and e-learning environments: connecting experiences and context. In: LOWRIE, Tom; JORGENSEN, Robyn (Eds.), Digital Games and Mathematics Learning Mathematics Education in the Digital Era, v. 4, p. 35-53, 2015.

MAYER, Richard E. Multimedia Learning. London, England: Cambridge University Press, 2001.

Computer games for learning: an evidence-based approach. London, England: MIT Press, 2014. 
Teoria cognitiva da aprendizagem multimídia e jogos digitais

MAYER, Richard E. Using Multimedia for e-learning. Journal of Computer Assisted Learning. v. 33, p. 403-423, Abr. 2017.

Disponivel em:

https://www.researchgate.net/publication/318179189_Using_multimedia_for_ e-learning_Multimedia_for_e-learning/citation/download. Acesso em: 11 jun. de 2020.

MORAN, José M. Educação e tecnologias: mudar para valer! 2013.

Disponivel em:

http://www.eca.usp.br/prof/moran/site/textos/tecnologias_eduacacao/educat ec.pdf. Acesso em: 22 jul. 2020.

Tablets para todos conseguirão mudar a escola? 2013.

Disponivel em:

http://www2.eca.usp.br/moran/wp-content/uploads/2014/03/tablets.pdf. Acesso em: 22 jul. de 2020.

PAIS, Luiz Carlos. Educação escolar e as tecnologias da informática. Belo Horizonte: Autêntica, 2005.

SÁ-SILVA, Jackson Ronie; ALMEIDA, Cristóvão Domingos de; GUINDANI, Joel Felipe. Pesquisa documental: pistas teóricas e metodológicas. Revista Brasileira de História \& Ciências Sociais, ano 1, n. 1, jul. 2009. 15p. Disponivel em: https://periodicos.furg.br/rbhcs/article/view/10351/pdf. Acesso em: 1 nov. 2020. 